\title{
PENGARUH MOTIVASI DAN PELATIHAN TERHADAP KINERJA KARYAWAN PADA PT GODREJ INDONESIA DI JAKARTA TIMUR
}

\author{
Phang Finny Liliana dan Carol Daniel Kadang \\ Program Studi Manajemen, Fakultas Ekonomi dan Bisnis, Universitas Tarumanagara Jakarta \\ Email:finnyliliana@yahoo.com
}

\begin{abstract}
This study aims to analyze the effect of motivation and training on employee performance at PT Godrej Indonesia in East Jakarta. This research was conducted with the method of Non Probability Sampling with purposive sampling type. Researchers distributed questionnaires to 100 employees of PT Godrej Indonesia. Data analysis using Smart PLS analysis. The results of the analysis concluded that motivation and training had a significant effect on the performance of employees of PT Godrej Indonesia in East Jakarta.
\end{abstract}

Keywords: motivation, training, performance.

Abstrak: Penelitian ini bertujuan untuk menganalisis pengaruh motivasi, dan pelatihan terhadap kinerja karyawan pada PT Godrej Indonesia di Jakarta Timur. Penelitian ini dilakukan dengan metode Non Probability Sampling dengan jenis purposive sampling. Peneliti menyebarkan kuesioner kepada 100 karyawan PT Godrej Indonesia. Analisis data menggunakan analisis Smart PLS. Hasil analisis menyimpulkan bahwa motivasi dan pelatihan berpengaruh signifikan terhadap kinerja karyawan PT Godrej Indonesia di Jakarta Timur.

Kata kunci: motivasi, pelatihan, kinerja.

\section{LATAR BELAKANG}

Sebuah perusahaan dituntut untuk menciptakan dimana perusahaan dapat bersaing secara sehat dengan melalui kinerja karyawan yang ada di dalam perusahaan. Seperti pada umum nya sebuah perusahaan bertujuan untuk mencapai laba sebesar besar nya agar perusahaan dapat terus bertahan ditengah semakin sulit nya ekonomi di dunia. Setiap sumber daya manusia yang ada didalam perusahaan harus mampu digunakan secara efisien dan efektif, karena sumber daya manusia yang ada adalah kunci sebuah perusahaan dapat melaju dengan sukses.

Sumber daya manusia (SDM) dalam perusahaan memiliki peran dan fungsi yang sangat penting bagi tercapainya tujuan perusahaan. SDM mencakup keseluruhan manusia yang ada dalam organisasi yaitu mereka yang terlibat dalam kegiatan operasional perusahaan mulai dari level yang paling bawah (lower management) hingga yang paling atas (top management). Meskipun berbeda level, namun seluruh elemen SDM tersebut memiliki peran yang sama terhadap tercapainya tujuan perusahaan. Pengabaian terhadap salah satu bagian berakibat terhambatnya pencapaian tujuan perusahaan. Kinerja adalah hasil kerja secara kualitas dan kuantitas yang dicapai oleh seorang karyawan dalam melaksanakan tugasnya sesuai dengan tanggung jawab yang diberikan kepadanya (Mangkunegara, 2013:18). Kinerja juga dapat merupakan tindakan atau pelaksanaan tugas yang telah diselesaikan oleh seseorang dalam kurun waktu tertentu dan dapat diukur.

Banyak faktor yang biasa mempengaruhi kinerja karyawan, dan saling berkaitan. Faktor yang mempengaruhi kinerja karyawan di antaranya adalah motivasi dan pelatihan 
kerja (Sweis, et al. 2019). Menurut Darmadi (2018:125), motivasi merupakan dorongan dasar yang menggerakkan seseorang bertingkah laku. Selain motivasi, faktor yang mempengaruhi kinerja karyawan adalah pelatihan (Sweis, et al. 2019). Pelatihan penting bagi perusahaan untuk meningkatkan kualitas karyawan dalam menjalankan tugasnya di dalam perusahaan. Perusahaan mengadakan pelatihan untuk menjadikan karyawannya lebih berkualitas sehingga tujuan perusahaan tersebut dapat tercapai. Salah satu tujuan dari pelatihan, baik ditujukan bagi karyawan lama atau karyawan baru adalah untuk tercapainya kesesuaian antara persyaratan yang dituntut oleh suatu pekerjaan dengan ketrampilan serta kompetensi karyawan. Hasil dari pelatihan

\section{KAJIAN TEORI}

Menurut Fahmi (2013:45), "motivasi kerja adalah aktivitas perilaku yang bekerja dalam usaha untuk memenuhi kebutuhan- kebutuhan yang diinginkan." Sedangkan menurut Darmadi (2018: 125): "Motivasi adalah kekuatan, baik dari dalam maupun dari luar yang mendorong seseorang untuk mencpai tujuan tertentu yang telah ditetapkan sebelumnya".

Menurut Dessler (2015:154) Pelatihan adalah "Proses mengajarkan karyawan baru atau yang ada sekarang, keterampilan dasar yang mereka butuhkan untuk menjalankan pekerjaan mereka”.

Menurut Dessler (2015:84) "kinerja karyawan merupakan prestasi kerja, yakni perbandingan antara hasil kerja yang dapat dilihat secara nyata dengan standar kerja yang telah ditetapkan organisasi”.

\section{Kaitan Antar Variabel}

\section{Pengaruh Motivasi Terhadap Kinerja Karyawan}

Penelitian yang dilakukan Handayani (2018) menunjukkan bahwa ada pengaruh secara positif dan signifikan antara motivasi kerja dengan kinerja karyawan. Motivasi merupakan faktor yang dapat mempengaruhi kinerja pegawai, kurangnya motivasi yang diberikan berdampak pada menurunnya kinerja pegawai. Penelitian Rakhmalina, dkk (2017) menyimpulkan adanya hasil yang positif dan signifikan antara motivasi kerja dengan kinerja karyawan. Kemudian penelitan yang dilakukan Erwin dan Suhardi (2020) juga menyimpulkan bahwa motivasi kerja berpengaruh secara signifikan dan positif terhadap kinerja karyawan. Setiap pegawai membutuhkan dorongan positif dalam melaksanakan pekerjaan. Kebutuhan individu ini akan mempengaruhi semangat kerjanya. Pemberian motivasi bertujuan untuk mendorong pegawai agar lebih semangat dan bergairah dalam bekerja. Semangat dan gairah kerja seorang pegawai dapat ditingkatkan dengan pemberian motivasi kerja yang tinggi. Jadi dengan memberikan motivasi dapat meningkatkan kinerja pegawai.

\section{Pengaruh Pelatihan Terhadap Kinerja Karyawan}

Penelitian Herli, et al (2018) menyatakan bahwa pelatihan berpengauh terhadap kinerja karyawan. Dengan adanya pelatihan para karyawan dapat mengembangkan kompetensinya dengan bertambahnya pengetahuan, keterampilan serta sikap kerja yang lebih baik. Kemudian dalam penelitian Khasanah, dkk., (2019) menyimpulkan bahwa pelatihan juga mempengaruhi kinerja karyawan karyawan. Pemberian program pelatihan yang efektif akan dapat memperbaiki sikap kerja karyawan menjadi terampil, ahli dan mampu melaksanakan tanggung jawabnya dengan semakin baik melalui pelatihan karyawan, kesempatan untuk meningkatkan kinerja karyawan semakin besar. 


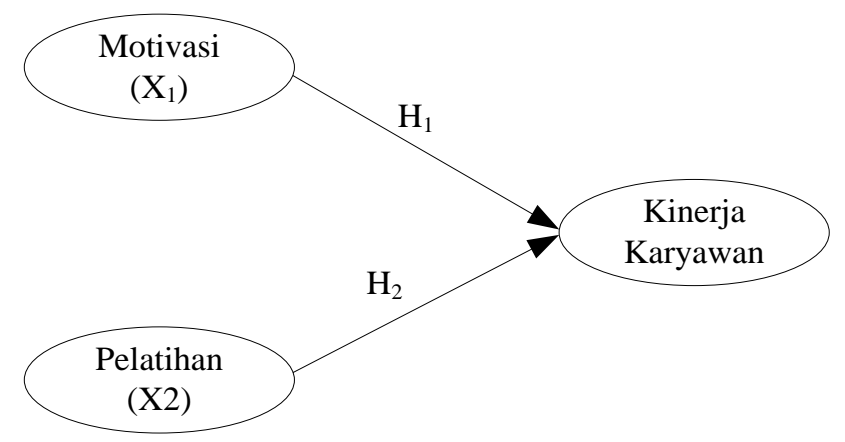

Gambar 1

Kerangka Pemikiran

berikut:

Berdasarkan kerangka pemikiran diatas maka hipotesis penelitian ini adalah sebagai

H1: Terdapat pengaruh yang signifikan motivasi terhadap kinerja karyawan.

$\mathrm{H} 2$ : $\quad$ Terdapat pengaruh yang signifikan pelatihan terhadap kinerja karyawan.

\section{METODE PENELITIAN}

Penelitian ini menggunakan disain penelitian deskriptif yang bertujuan membuat deskriptif secara sistematis, faktual, dan akurat mengenai fakta-fakta dan sifat-sifat dari populasi. Populasi dalam penelitian ini adalah seluruh karyawan PT Godrej Indonesia sebanyak 135 karyawan Pengambilan sampel diambil dengan menggunakan metode jenis purposive sampling, karena didalam menentukan sampel ada pertimbangan kriteria tertentu. Jumlah sampel sebanyak 100 responden.

Data dianalisis menggunakan PLS-SEM dimana data diolah dengan program software SmartPLS 3. Pertama, pengolahan dilakukan pada outer model untuk menguji validitas (konvergen dan diskriminan) dan reliabilitas. Uji validitas konvergen dilihat dari nilai outer loadings di antara 0,5-0,7 kemudian AVE > 0,5. Selanjutnya untuk uji validitas diskriminan, beracuan pada Fornell-Larcker Criterion dan Cross Loadings Ghozali (2014:52). Kemudian pada analisis reliabilitas, beracuan pada nilai cronbach's alpha dan composite reliability > 0,7 .

Kedua, pengolahan dilakukan pada inner model untuk menguji hipotesis yang telah dihasilkan. Sebelum pengujian hipotesis, pertama dilakukan pengujian hubungan antar konstruk dengan melihat nilai $\mathrm{R}$-square $\left(\mathrm{R}^{2}\right)$ dengan kriteria $(1-0,75)$ "bersifat kuat", $(0,74$ - 0,5) "bersifat moderat", dan $(0,49-0,25)$ "bersifat lemah", nilai $\mathrm{Q}$-square $\left(\mathrm{Q}^{2}\right)$ dengan kriteria $\mathrm{Q}^{2}>0$ "memiliki kemampuan prediksi", dan nilai GoF (Goodness of Fit) dengan kriteria 0,1 "kelayakan model kecil", 0,25 "kelayakan model sedang", dan 0,36 "kelayakan model besar". Selanjutnya pengujian hipotesis, untuk melihat pengaruh yang terjadi lihat (positif/ negatif) dari coefficient yang dihasilkan, dan menggunakan $t$-statistics $>1,645$ (hipotesis tidak ditolak) dan $p$-values $<0,05$ (hipotesis signifikan) (Ghozali, 2014:50).

\section{HASIL UJI STATISTIK}

\section{Hasil Uji validitas}

Pada hasil validitas konvergen, didapatkan semua angka $>0,7$ pada nilai outer loadings untuk setiap pernyataannya, dan didapatkan semua angka $>0,5$ pada nilai Average Variance Extracted / AVE maka pernyataan yang digunakan sudah valid secara validitas konvergen. Selain itu, pada hasil validitas diskriminan, peneliti menggunakan nilai Cross Loadings dimana nilai korelasi antara pernyataan terhadap variabel nya sendiri harus lebih 
besar daripada pernyataan terhadap variabel lainnya berdasarkan hasil kalkulasi SmartPLS 3, didapatkan semua angka pada pernyataan terhadap variabel-nya sendiri lebih besar daripada terhadap variabel lainnya maka pernyataan sudah valid secara validitas diskriminan.

Tabel 1

Avarage Variance Extracted

\begin{tabular}{|l|c|}
\hline & $\begin{array}{c}\text { Avarage Variance } \\
\text { Extracted }\end{array}$ \\
\hline Kinerja & 0,773 \\
\hline Motivasi & 0,702 \\
\hline Pelatihan & 0,710 \\
\hline
\end{tabular}

Sumber: Olahan data smartPLS 3.00

Hasil uji Reliabilitas

Tabel 2. Hasil Uji Reliabilitas

\begin{tabular}{|l|c|c|}
\hline & $\begin{array}{c}\text { Composite } \\
\text { Reliability }\end{array}$ & Cronbach's Alpha \\
\hline Kinerja & 0,960 & 0,951 \\
\hline Motivasi & 0,966 & 0,961 \\
\hline Pelatihan & 0,961 & 0,954 \\
\hline
\end{tabular}

Pada hasil reliabilitas, maka berdasarkan hasil yang dikalkulasi oleh program SmartPLS 3, didapatkan semua angka pada nilai Cronbach's Alpha untuk setiap pernyataannya adalah $>0,7$ dan pada nilai Composite Reliability didapatkan semua angka untuk setiap pernyataannya adalah $>0,7$. Maka pernyataan yang digunakan dalam penelitian ini sudah reliabel berdasarkan kedua nilai reliabilitas, yakni Cronbach's Alpha dan Composite Reliability. 


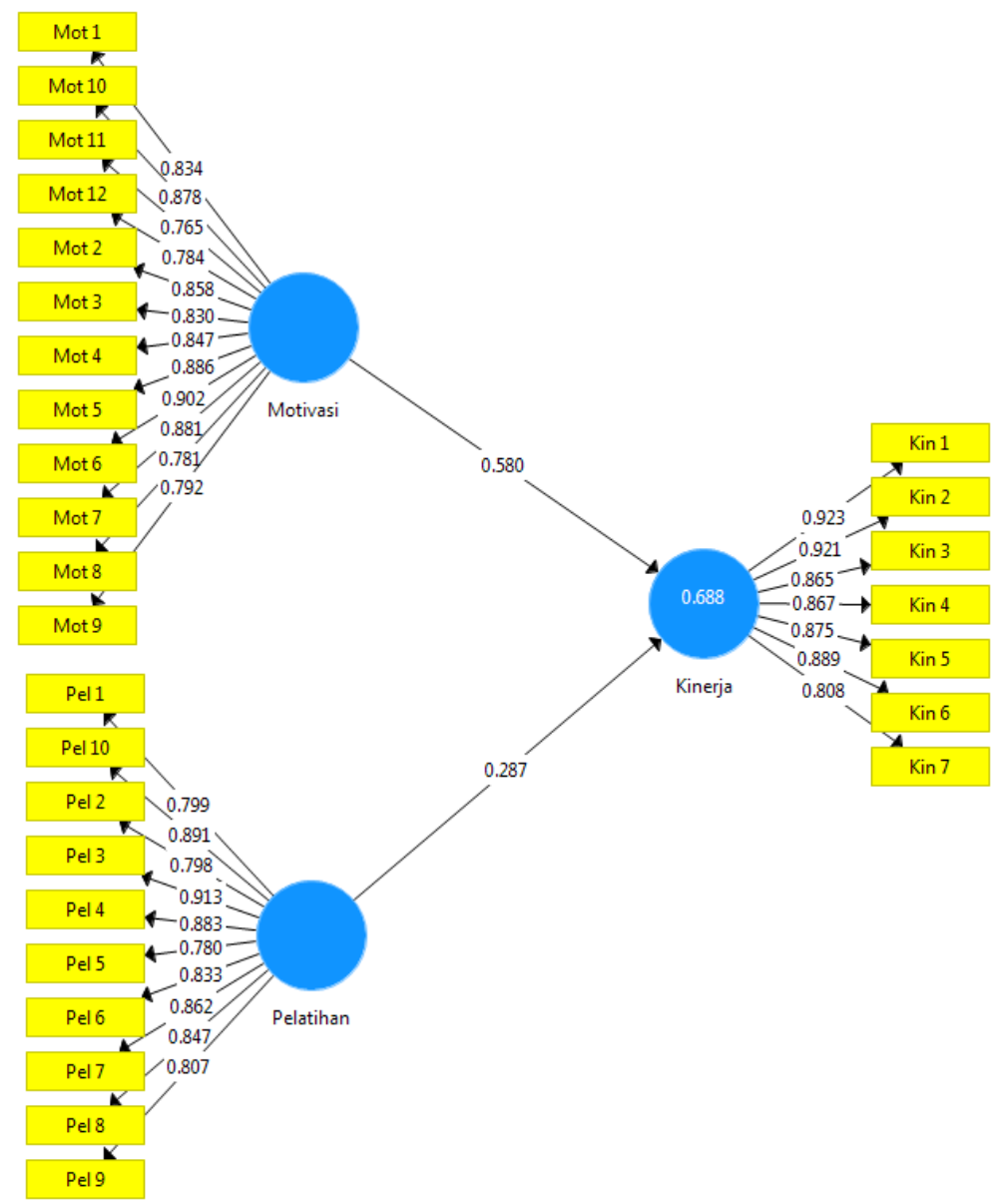

Gambar 2

Diagram Loading Factors

\section{Hasil Uji R-Square ( $\mathbf{R}^{2}$ ), Q-square, f-square dan GoF (Goodness of Fit)}

Tabel 3. Output R-Square

\begin{tabular}{|c|c|}
\hline & R-square \\
\hline Kinerja & 0.688 \\
\hline
\end{tabular}

Sumber: Hasil Pengolahan Data SmartPLS (PLS Algorithm)

Berdasarkan hasil pada tabel diatas, dapat dijelaskan bahwa variabel motivasi dan pelatihan memiliki pengaruh yang cukup kuat terhadap kinerja karyawan yaitu 68,8\%, sedangkan sisanya yaitu $31,2 \%$ dipengaruhi oleh variabel lain yang tidak ada dalam penelitian ini.

Tabel 4. Tabel $Q$-Square

\begin{tabular}{|c|c|}
\hline & $Q$-Square \\
\hline Kinerja Usaha & 0.488 \\
\hline
\end{tabular}

Sumber: Hasil Pengolahan Data SmartPLS (Blindfolding)

Berdasarkan dari hasil pada tabel diatas, dapat dijelaskan bahwa variabel media sosial dan manajemen pengetahuan memiliki pengaruh yang cukup kuat terhadap kinerja usaha yaitu dengan nilai sebesar 0.488 


\section{Hasil Pengujian Goodness of Fit (GoF)}

Untuk dapat melakukan pengujian kecocokan model dalam penelitian ini, nilai GoF (GooUntuk dapat melakukan pengujian kecocokan model dalam penelitian ini, nilai GoF (Goodness of Fit) dapat dihitung dengan cara manual dengan memasukan nilai AVE dan nilai koefisien determinasi. Berikut ini merupakan perhitungan nilai Goodness of Fit (GoF):

$$
\begin{aligned}
& \overline{A V E}=0,728 \\
& \overline{R^{2}}=0,688 \\
& G O F=\sqrt{\overline{A V E} \times \overline{R^{2}}} \\
& G O F=\sqrt{0,728 \times 0,688} \\
& G O F=0,707
\end{aligned}
$$

Berdasarkan hasil dari perhitungan Goodness of Fit (GoF) diatas, maka dapat disimpulkan bahwa model yang dapat digunakan dalam penelitian ini kecocokan model penelitian yang

\begin{tabular}{|c|c|c|c|c|c|}
\hline & $\begin{array}{l}\text { Original } \\
\text { Sample (O) }\end{array}$ & $\begin{array}{l}\text { Sample } \\
\text { Mean (M) }\end{array}$ & $\begin{array}{l}\text { Standar } \\
\text { Deviation } \\
\text { (STDEV) }\end{array}$ & $\begin{array}{l}\text { T Statistics } \\
\text { (JO/STDEV) }\end{array}$ & $\begin{array}{l}\mathrm{P} \\
\text { Value }\end{array}$ \\
\hline $\begin{array}{l}\text { Motivasi } \rightarrow \text { Kinerja } \\
\text { karyawan }\end{array}$ & 0.580 & 0.581 & 0.101 & 5.742 & 0.000 \\
\hline $\begin{array}{l}\text { Pelatihan } \rightarrow \text { Kinerja } \\
\text { Karyawan }\end{array}$ & 0.287 & 0.290 & 0.094 & 3.051 & 0.002 \\
\hline
\end{tabular}
tergolong besar. Nilai GoF 0,1 tergolong kecil, nilai GoF 0,25 tergolong sedang dan nilai GoF lebih dari 0,38 tergolong besar

\section{Hasil Uji Hipotesis}

Tabel 5. Hasil Uji Hipotesis (Bootstrapping)

Sumber: Hasil Olah Data pada SmartPLS3

Berdasarkan hasil dari pengujian variabel motivasi terhadap kinerja karyawan, maka dapat disimpulkan bahwa $\mathrm{H}_{1}$ tidak ditolak karena motivasi mempunyai nilai t-statistik sebesar 5,742 dan nilai p-values sebesar 0,000. Nilai t-statistik tersebut lebih besar dari pada batas nilai kriteria yaitu 1,96 dan nilai p-values harus lebih kecil dari 0,05 atau 5\%. Sehingga dapat dikatakan bahwa variabel motivasi berpengaruh secara signifikan terhadap kinerja karyawan..

Berdasarkan hasil dari pengujian variabel pelatihan terhadap kinerja karyawan, maka dapat disimpulkan bahwa $\mathrm{H}_{2}$ tidak ditolak karena pelatihan mempunyai nilai t-statistik sebesar 3,051 dan nilai p-values sebesar 0,002. Nilai t-statistik tersebut lebih besar dari pada batas nilai kriteria yaitu 1,96 dan nilai p-values harus lebih kecil dari 0,05 atau 5\%. Sehingga dapat dikatakan bahwa variabel pelatihan berpengaruh secara signifikan terhadap kinerja karyawan karyawan.

\section{DISKUSI}

Hipotesis yang pertama menunjukkan bahwa variabel motivasi terbukti berpengaruh secara signifikan terhadap kinerja karyawan karena hasil dari nilai t-statistik kompensasi sebesar 5,742 yang berarti lebih besar dari 1,96 dan p-values kompensasi sebesar 0,000 yang berarti lebih kecil dari 0,05. Sehingga dapat disimpulkan bahwa motivasi memiliki pengaruh yang signifikan terhadap kinerja karyawan. Hal tersebut sesuai dengan penelitian yang telah dilakukan Handayani (2018), Rakhmalina (2017) dan Erwin dan Suhardi (2020) yang menyimpulkan bahwa motivasi berpengaruh terhadap kinerja karyawan. Dalam organisasi seorang pegawai dituntut untuk lebih giat dan aktif dalam bekerja. Untuk mencapai hal 
tersebut diperlukan adanya motivasi dalam melakukan pekerjaan, karena seorang pegawai yang mempunyai motivasi kerja yang tinggi biasanya mempunyai kinerja yang tinggi pula. Motivasi merupakan faktor yang dapat mempengaruhi kinerja pegawai, kurangnya motivasi yang diberikan berdampak pada menurunnya kinerja pegawai

Untuk hipotesis kedua, dapat disimpulkan pelatihan memiliki pengaruh yang signifikan terhadap kinerja karyawan dengan tingkat keyakinan 95\%, karena hasil dari nilai t-statistik lingkungan kerja sebesar 3,051 yang berarti lebih besar dari 1,96 dan p-values culture sebesar 0,002 yang berarti lebih kecil dari 0,05. Hasil penelitian ini sejalan dengan penelitian Herli, et al (2018) dan Khasanah, dkk., (2019) yang menyimpulkan bahwa pelatihan berpengaruh terhadap kinerja karyawan. Pelatihan yang merupakan suatu proses pembelajaran untuk memperoleh keahlian, konsep, peraturan, atau sikap dalam rangka meningkatkan kinerja karyawan. Melalui pelatihan kerja, kemampuan pegawai akan meningkat, sehingga pekerjaan yang dibebankan pada masing-masing pegawai diharapkan dapat cepat selesai dengan hasil yang memuaskan. Oleh sebab itu pelatihan kerja juga berperan penting dalam peningkatan kemampuan dan kinerja yang dihasilkan oleh karyawan. Sehingga kinerja yang dihasilkan oleh karyawan akan lebih baik dan maksimal.

\section{PENUTUP}

Berdasarkan hasil analisis dan pembahasan, dapat disimpulkan bahwa:

1. Terdapat pengaruh yang signifikan antara motivasi terhadap kinerja karyawan PT. Godrej Indonesia. Semakin baik Motivasi yang diberikan oleh perusahaan maka akan semakin meningkatkan kinerja karyawan.

2. Terdapat pengaruh yang signifikan antara pelatihan terhadap kinerja karyawan PT. Godrej Indonesia. Artinya, pelatihan yang diterima oleh para karyawan dapat meningkatkan kinerja karyawan yang pada akhirnya dapat meningkatkna kinerja perusahaan.

Setelah meneliti dan mengetahui permasalahan yang ada, maka saran yang dapat diberikan bagi perusahaan dan bagi peneliti lain yaitu

1. Perusahaan dapat meningkatkan kinerja karyawan dengan cara mengusahakan motivasi kerja yang baik. Perusahaan sebaiknya lebih meningkatkan gaji yang diberikan kepada karyawan., karena hal tersebut merupakan indikator yang paling rendah pengaruhnya terhadap kinerja karyawan. Karena dengan gaji yang cukup untuk karyawan akan meningkatkan kinerja karyawan.

2. Selain itu perusahaan diharapkan dapat memberikan pelatihan berkala terhadap karyawan. Dengan pelatihan tersebut maka akan dapat meningkatkan kemampuan dan ketrampilan karyawan yang pada akhirnya juga akan meningkatkan kinerja mereka.

\section{DAFTAR PUSTAKA}

Darmadi (2018) Manajemen Sumber Daya Manusia. Yogyakarta: Budi Utama Dessler, Gary. (2015). Manajemen sumber daya manusia. Jakarta: Salemba Empat Erwin dan Suhardi (2020) Pengaruh Motivasi Dan Pelatihan Terhadap Kinerja Karyawan PT Wonder Trend Indonesia. Jurnal EMBA. 8 (3): 144 -153

Fahmi, Irham. (2014). Perilaku Organisasi: Teori, Aplikasi, dan Kasus. Cetakan Kedua. Bandung: Alfabeta.

Ghozali, Imam (2014) Structural Equation Modeling - Metode Alternatif dengan Partial Least Squares (PLS). Semarang: Badan Penerbit Universitas Diponegoro

Handayani, Rima (2018) The Effect of Training and Motivation on Employee Performance . Pinisi Discretion Review . 2 (1): 25- 32 
Herli, Ania, Hubeis Aida Vitayala dan Kuswanto Sadikin (2018) The Effect Of Training And Motivation On Employee Performance Of PT Asuransi XYZ. Russian Journal of Agricultural and Socio-Economic. 6 (78):177-184

Khasanah, Uswatun, Fauzan Muttaqien dan Noer Aisyah Barlian (2019) Pengaruh Pelatihan Kerja dan Motivasi Kerja Terhadap Kinerja Karyawan KUD Tani Makmur di Kecamatan Senduro Kabupaten Lumajang. Progress Conference. 2 (1) : 452-459

Mangkunegara, Anwar Prabu (2013), Manajemen Sumber Daya Manusia Perusahaan. Bandung: Remaja Rosdakarya.

Rakhmalina, Ika, Emelda Harapin Hafid dan Periansya (2017) Influence of Motivation and Job Training The Performance of Employees PT. RB Sukasada Palembang. Jurnal Terapan Manajemen dan Bisnis. 3 (2):147-153

Sweis, Rateb J, Razan Ghalion, Mohammad El- Mashaleh, Israa Amayreh, Al- Sayed Niveen, Wasiim Al Balkhi (2019) The Effects Of Training And Motivating Employees On Improving Performance Of Construction Companies: The Case Of Jordan. International Journal of Information, Business and Management. 11 (2): 179-211 